\title{
Fouling detection in a shell and tube heat exchanger using variation of its thermal impulse responses : methodological approach and numerical verification
}

\author{
Waseem Al Hadad ${ }^{\mathrm{a}, \mathrm{b}}$, Vincent Schick ${ }^{\mathrm{a}, \mathrm{b}}$, Denis Maillet $\mathrm{e}^{\mathrm{a}, \mathrm{b}^{*}}$ \\ aUniversité de Lorraine, LEMTA, ENSEM, 2 Avenue de la Forêt de Haye, BP 90161, \\ 54505 Vandoeuvre-lès-Nancy cedex, France

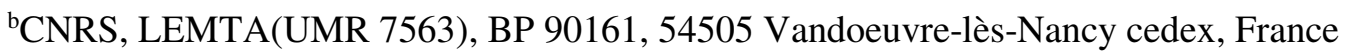

\begin{abstract}
A new method for fouling detection in a heat exchanger is proposed. This method is based on the sensitivity of its impulse response (time version of its transfer function) with fouling. The concept is validated here numerically for a shell and tube heat exchanger in steady state regime, perturbed thermally by a transient surface source. This method is presented here, on a theoretical ground. It can be implemented online, whatever the geometric and structural characteristics of the setup. It only requires the use of regular temperature sensors and actuators. The only condition concern the equations of the model of the heat exchanger which have to be linear with time invariant coefficients.
\end{abstract}

Keywords: Heat exchanger, fouling detection, impulse response, transfer function, deconvolution, conjugate heat transfer.

\section{Nomenclature}

a thermal diffusivity, $\mathrm{m}^{2} \cdot \mathrm{s}^{-1}$

D diameter, $\mathrm{m}$

e thickness, $\mathrm{m}$

$h \quad$ heat transfer coefficient, $\mathrm{W} \cdot \mathrm{m}^{-2} \cdot \mathrm{K}^{-1}$

$H \quad$ impulse response

$\ell \quad$ length, $\mathrm{m}$

$n \quad$ normal outward pointing unit vector

$p \quad$ Laplace parameter, $\mathrm{s}^{-1}$

$P \quad$ Pressure, $\mathrm{Pa}$

$P e \quad$ Péclet number

$\mathrm{Pr} \quad$ Prandtl number

$q \quad$ surface heat source, $\mathrm{W} \cdot \mathrm{m}^{-2}$

$q_{f l u x}, \boldsymbol{q}_{f l u x}$ wall heat flux, heat flux vector, W.m ${ }^{-2}$

$\dot{Q}_{v} \quad$ volume flow rate, $\mathrm{m}^{3} \cdot \mathrm{s}^{-1}$

Re Reynolds number

$T \quad$ temperature, $\mathrm{K}$

$u \quad$ input, thermal excitation, source

$U \quad$ overal heat transfer coefficient, $\mathrm{W} \cdot \mathrm{m}^{-2} \cdot \mathrm{K}^{-1}$

$U_{m} \quad$ mean velocity, $\mathrm{m} . \mathrm{s}^{-1}$

$\boldsymbol{v} \quad$ velocity field, $\mathrm{m} \cdot \mathrm{s}^{-1}$

$x, y, z \quad$ space coordinates, $\mathrm{m}$

Corresponding author. Tel. :(+33)3 72744322 ; fax :+33 383595551

Email address: denis.maillet@univ-lorraine.fr (Denis Maillet ) 
output, consequence, response

thermal impedance

\section{Greek symbols}

$\begin{array}{ll}\lambda & \text { thermal conductivity, } \mathrm{W} \cdot \mathrm{m}^{-1} \cdot \mathrm{K}^{-1} \\ \rho & \text { density, } \mathrm{kg} \cdot \mathrm{m}^{-3} \\ \theta & \text { temperature variation, } \mathrm{K} \\ \vartheta & \text { viscosity, } \mathrm{m}^{2} \cdot \mathrm{s}^{-1}\end{array}$

\section{Superscripts and subscripts}

$\begin{array}{ll}- & \text { Laplace transform } \\ c & \text { cold } \\ f & \text { fluid } \\ h & \text { hot } \\ \text { in } & \text { inlet } \\ \text { out } & \text { outlet } \\ p & \text { point on external wall } \\ s & \text { solid } \\ \text { ss } & \text { steady state }\end{array}$

\section{Introduction}

During the operation of a heat exchanger, deposits may develop over the wall that separates the hot and cold fluids. Over time, these materials, which are either layers sticked to the walls or porous materials in the volume of the flow, appear and grow along the length of wall or/and in specific areas. They can thus block or change the flow direction. Furthermore, they are less conductive than the separating. Therefore, they will significantly reduce the heat transfer efficiency and performance in the course of time.

In the literature, this undesirable fouling layer degrades the operation of the heat exchanger and one of the major difficulties is the early quantification (prediction) or detection of this undesirable layer. Fouling quantification is always more difficult than fouling detection. This difficulty comes from the random behavior of this phenomenon.

There are various methods to slow down the presence and accumulation of fouling (filtering, chemical treatment, ..) [1,2]. As soon as the fouling takes place, the complete cleaning of the installation becomes essential. The systematic periodic cleaning to remove fouling is not the best solution. If the period is short, the costs of production shutdown, that is production losses during cleaning and maintenance tasks (cleaning, disassembly,...), can increase. On the contrary, if the this period is long, fouling can cause an increase of the energy consumed by the process (the heat exchanger efficiency decreases with fouling), an increase in the consumption of cooling fluid and an impact on the environment. For all these reasons, the manufacturers of heat exchangers and their customers seek to move thus from systematic maintenance to predictive maintenance.

Apart from the methods based on models of the black box type, such as neural networks [3], popular methods of fouling detection are based on the decrease in the Overall Heat Transfer Coefficient, noted $U$. In some configurations, this method is not precise enough. This can be explained by the fact that the models used for explaining $U$ are based on a strong assumption (locally 1D transfer which consists in neglecting the axial heat transfer in the solid walls) and by the compensation that can take place between the resistances to conduction and advection : the fouling layer tends to increase the resistance to conduction (due to the increase of the wall thickness) and to decrease the resistance to convective heat transfer (with fouling, the hydraulic diameter decreases, which increases the internal velocity if the flow rate is imposed and that will 
lead to an increase of convective heat transfer coefficient). Therefore, the overall exchange coefficient does not always have a good sensitivity to fouling [4]. Another classical method of detection, easy to implement, is based on the increase in pressure loss when the flow rate is imposed but the effectiveness of this method depends on the type of exchanger [5].

Improved results can be reached if one uses transient regimes, such as a steep variation of one of the flowrates, which allows a better followed up of the Overal heat transfer coefficient, using dynamic models and state estimation through Kalman filterng, see [6,7] or variation of the fluid inlet temperatures [8]. Another possibility is to work in modulated regime, using perturbations of the flowrates or inlet temperatures $[9,10]$, which allows the acquisition of signals of good signal to noise ratios through lock-in techniques.

A common approach for fouling detection consists in comparing experimental temperatures with those predicted by a reduced model developed earlier [11], [12]. Recently Palmer et al. [13, 7] attempted to quantify fouling in a cross-flow plate fin heat exchanger. The idea was based on the minimization of the differences between the measured temperatures and their predictions by a model that takes fouling into account. We point out here the common simplifying assumptions in these works : the fluid flow was considered one-dimensional along each fluid direction, the axial heat conduction along the fluid was considered negligible and the convective heat transfer coefficient was considered uniform along each fluid direction and the heat transfer between the two fluids was locally 1D. The conduction in the walls has been neglected in [11] and [12] and considered 2D in [13] (with a zero temperature gradient in the direction of the thickness).

It should be emphasized that in the case where the Péclet number Pe is small with non negligible thickness of the walls and short channels, the axial conduction in these walls plays a very important role $[14,15,16]$. So, under these circumstances, these methods do not provide a good detection of fouling.

There are also sophisticated methods that have been developed to detect fouling, such as silicon sensors [17], ultrasonic, acoustic and optical techniques [18]. These methods which require a specific instrumentation, are not always adapted to the equipment and are therefore limited to a laboratory use.

So, the challenge is to be able to detect fouling in real time, without stopping the process and implementable at both the laboratory and industrial scales.

In this work, we propose a detection technique based also on comparison of experimental measurements and outputs of a reference model, that is identifying the impulse response of the system. The use of this concept of impulse response is based on the only assumption that the system of equations that model the response of the system to a perturbation is linear, with time invariant coefficients (LTI). This means that this type of method could allow getting rid of the other a priori arbitrary asumptions required by the models used in the detection methods analyzed above, which could add some robustness to it.

So in the detection technique proposed here, we compare the system signature obtained experimentally during operation with the reference signature. This reference model must be identified previously from a calibration experiment when the exchanger is clean. This signature or model has a convolutive nature, which is valid for a LTI system. The system signature corresponds here to its impulse responses or its transfer functions (the transfer function is the Laplace transform of the impulse response).

These functions, which can be identified whatever the geometric complexity (conjugated heat transfer, turbulent, flow direction change, roughness, development of the boundary layer,..), depend only on the geometry, of the velocity field of the flowing fluids and of the correponding thermo-physical properties. These features can therefore be used to detect the temporal variation of a structural parameter of the system during operation. In our previous works, we have shown the interest of transfer functions for LTI systems where heat diffusion and advection occur in a conjugated way, both on a theoretical [19] and on an experimental $[20,21]$ basis. These are either impedances relating a local or averaged temperature to the cause of its variation, that is an unsteady heat source, or a "transmittance" linking a local or averaged temperature to another one whose variation occurs before. In that last case, the prior variating local temperature will be called a "pseudo-source" here, since it is also the consequence of the common heat source. 
Our paper is organized as follows : in section 2, we show how the transfer function can be identified whatever the geometry and how it can be used to detect the possible presence of fouling. In section 3 , we present the studied system (shell and tube heat exchanger) used in this work to validate the thermal fouling detector. In section 4, we apply this methodology to the model of the above system, using Finite Element simulations [22].

\section{Impulse response identification and principle of a thermal fouling detector}

This section presents the general concept of identification of the impulse response of a linear and time invariant

system (LTI), using the knowledge of both input (the perturbation) and output (the corresponding response).

Once an impulse response has been identified for such a system (a calibration), its re-identification at a later time, with comparison with its prior values, gives information about a possible change of one of its structural parameter (a non destructive test). This principle will be applied to a shell and tube heat exchanger in the next chapters.

In one of our works just cited above [19], we focused on a physical system modeled by a LTI mathematical system composed of a partial differential equation, such as the heat equation and of its associated boundary and interface conditions. We showed that, for such a system, the output (response or consequence) $y$ at a given point, or its average in any subsurface or subdomain, is a simple product in Laplace domain, or a convolution product in time domain, between the input (excitation or cause) $u$ and a corresponding function $H$ :

$$
\begin{aligned}
& \bar{y}(p)=\bar{H}(p) \bar{u}(p) \quad \text { (Laplace domain) } \\
& y(t)=H(\mathrm{t}) * u(t) \quad \text { (time domain) }
\end{aligned}
$$

where the upper bar (-) denotes the Laplace transform and $p$ the Laplace parameter :

$$
\bar{\psi}(p)=\int_{0}^{\infty} \psi(t) \exp (-p t) \mathrm{d} t \text { for } \psi=y, H \text { or } u
$$

Function $H(\mathrm{t})$ is the impulse response, while its Laplace transform $\bar{H}(p)$ is the corresponding transfer function. The star $(*)$ denotes the convolution product.

The convolution product (1b) can be defined in two different ways, using its commutative property [23] :

$$
y(t)=\int_{0}^{t} H\left(t-t^{\prime}\right) u\left(t^{\prime}\right) \mathrm{d} t^{\prime}
$$

or

$$
y(t)=\int_{0}^{t} u\left(t-t^{\prime}\right) H(t) \mathrm{d} t^{\prime}
$$

Parameterization of the excitation $u\left(t^{\prime}\right)$, over a basis of piecewise constant functions defined on a constant time step $\Delta t=t_{\text {final }} / N_{t}$, where $t_{\text {final }}$ is the duration of the response and $N_{t}$ the number of time steps, allows a sampling $y\left(t_{k}\right)=k \Delta t$ of the response, for times $t_{k}=k \Delta t$ (for $k=1$ to $N_{t}$ ). This can be put under a column vector/matrix form:

$$
\boldsymbol{y}=\mathbf{M}(\boldsymbol{H}) \boldsymbol{u}
$$


We use the commutative property of the convolution product here :

$$
\boldsymbol{y}=\mathbf{M}(\boldsymbol{u}) \boldsymbol{H}
$$

with

$$
\mathbf{M}(\boldsymbol{\psi})=\Delta t\left[\begin{array}{ccccc}
\psi_{1} & 0 & 0 & \ldots & 0 \\
\psi_{2} & \psi_{1} & 0 & \ddots & \vdots \\
\psi_{3} & \psi_{2} & \psi_{1} & \ddots & 0 \\
\vdots & \vdots & \vdots & \ddots & \vdots \\
\psi_{N_{t}} & \psi_{N_{t}-1} & \psi_{N_{t}-2} & \ldots & \psi_{1}
\end{array}\right] \quad \text { with } \quad \boldsymbol{\psi}=\left[\begin{array}{c}
\psi_{1} \\
\psi_{2} \\
\psi_{3} \\
\vdots \\
\psi_{N_{t}}
\end{array}\right]
$$

and

$$
\psi_{k}=\frac{1}{\Delta t} \int_{t_{k-1}}^{t_{k}} \psi(t) \mathrm{d} t \approx \frac{1}{2}\left(\psi\left(t_{k}\right)+\psi\left(t_{k-1}\right)\right) \text { for } \psi=u \text { or } H
$$

with $t_{0}=0, \psi\left(t_{0}\right)=0$ and $k=1$ to $N_{t}$. Here $\mathbf{M}($.$) is a function whose value is a square matrix of size$ $N_{t} \times N_{t}$ (a lower triangular Toeplitz matrix) that depends on a column vector, either $\boldsymbol{H}$ or $\boldsymbol{u}$.

Let us note that the numerical quadrature, in equations (3a) and (3b), of the convolution products (2a) and (2b) respectively, is only valid for a time step small enough with respect to the chararactistic times of both input $u(t)$ and impulse response. We also assume that these two functions are continuous and bounded over the $\left[0, t_{\text {final }}\right]$ interval. If there is a discontinuity at time $t_{0}=0$ (case met if $\psi(t)$ is a step function), the first coefficient of vector $\psi$ gets the following value : $\psi_{1}=\psi\left(t_{1}\right)$.

So, if both input and output are known, the impulse response $\boldsymbol{H}$ can be identified by inverting the Toeplitz matrix of the source, that is $\mathbf{M}(\boldsymbol{u})$, see equation (3b).

Once the impulse response has been identified for a given system, it can be considered as its identity card : the impulse response is an intrinsic quantity that depends only on the structural characteristics of the system : dimensions (wall thickness, length, diameter, etc.), thermophysical properties and internal velocity field.

During the system operation, if the impulse response has changed, this can be explained by a change in the structural parameters of the system.

In the case of a heat exchanger, such a change may stem from a change of one of the fluid mass flow rates or from the apparition of fouling. On this basis, a thermal detection method can be designed for fouling. Its principle can be summarized in the following steps :

1. The type of thermal perturbation $u(t)$ and the location of its application have to be chosen, together with the place the output $y(t)$ is obseved. This perturbation should be small enough in order for the response of the system to stay in the linear domain.

2. The impulse response $H_{\text {clean }}(t)$ is identified when the system is clean or new, for given mass flow rates of the fluids.

3. This impulse response, called now $H_{\text {operation }}(t)$, is re-identified, for the same values of the mass flow rates, and a possible different input. This can be made in a periodical way during operation 
4. If substantial differences appear between $H_{\text {operation }}(t)$ and $H_{\text {clean }}(t)$, an ageing of the system, such as fouling, has happened.

This principle of fouling detection will be verified numerically in the next sections for a tube and hell heat exchanger.

Remark : For some specific temporal forms of the source $u(t)$ the transfer function and the corresponding impulse response, can be calculated without using the solution of the vector/matrix linear system ( $3 \mathrm{~b}$ ). This alternate method, which is semi-analytic, is possible only for a temporal source form corresponding to available explicit inverse Laplace transforms of both source and response.

Here, we consider the excitations of the following forms: a Dirac pulse, a step and a ramp. For these special excitation forms $u(t)$ and from equation (1a), one can calculate semi-analytically the corresponding temporal transfer function $H(t)$ using the corresponding responses, see Table 1. These expressions of $H(t)$ are valid only in cases where the response is not instantaneous, that is $\frac{\mathrm{d} y}{\mathrm{~d} t}\left(t=0^{+}\right)=0$.

\section{Table 1}

Alternate method for identifying the impulse response $H(t)$ starting from responses $y(t)$ to specific source forms $u(t)$

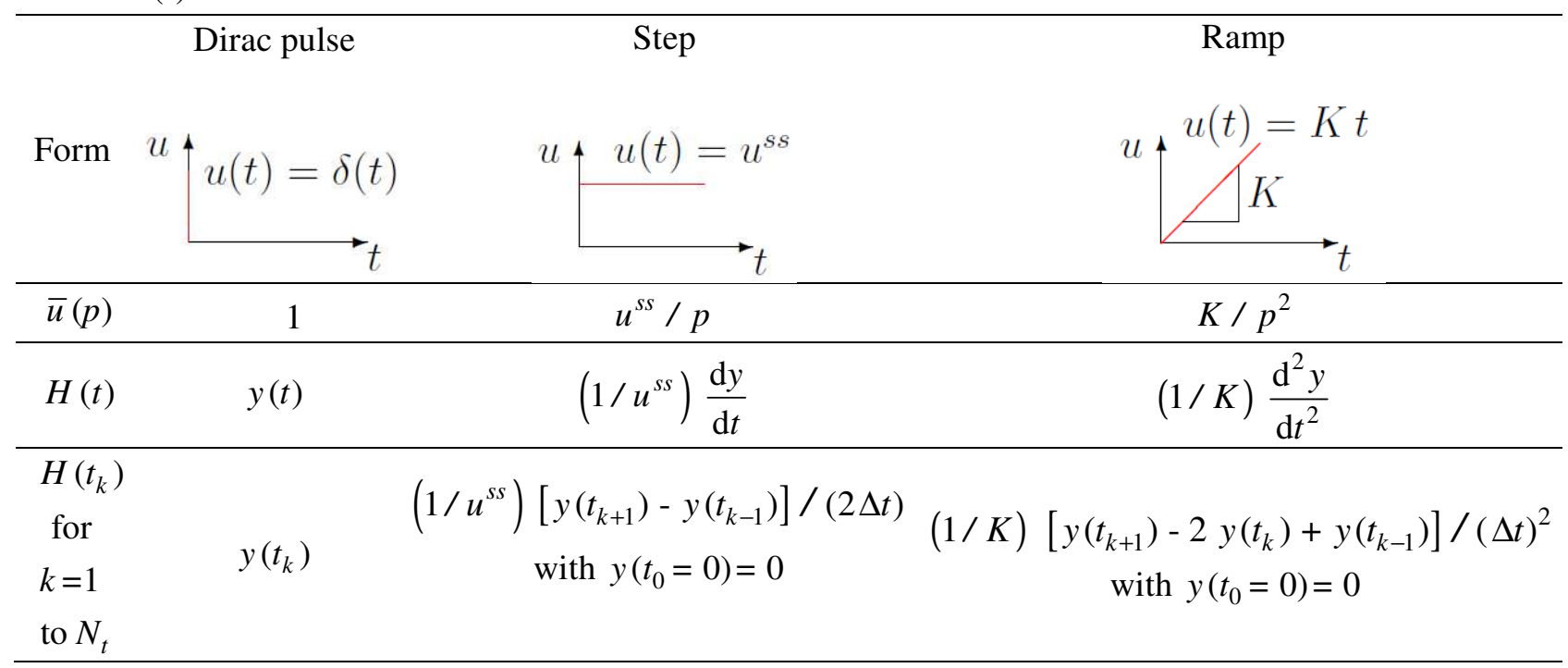

\section{Studied system and its equations}

Let us consider a tube and shell heat exchanger of length $\ell_{1}$, of inlet/outlet tube diameters $D_{1}$, of shell diameter $D_{2}$, of inlet/outlet shell-side diameters $D_{3}$ and of wall thickness (tube, shell and baffles) $e$, see Figure 1. We assume that the circulating fluids in the tube (hot fluid) and in the shell (cold fluid) are incompressible.

We also assume that the heat exchanger initially operates in steady state and at a given moment, the transfer is perturbed by a surface heat source, $q(t)$ which is uniformly distributed over the outer lateral surface of the inlet hot fluid pipe over a length $\ell_{3}$, see Figure 1. In this application, $q(t)$ corresponds to the input denoted by $u(t)$ in the general presentation in section 2 .

The two volume flow rates are assumed to remain constant in time during the thermal perturbation and both fluid and solid walls have thermophysical properties that are supposed to be independent of temperature : the equations of motion can be solved independently of the heat equation. The flow in the tube is assumed to be 
laminar $(\operatorname{Re}<2000)$ and is described by the classical conservative equations of mass and momentum. Turbulence in the shell is taken into account through the $k-\varepsilon$ model [24] :

$$
\nabla \cdot v=0
$$
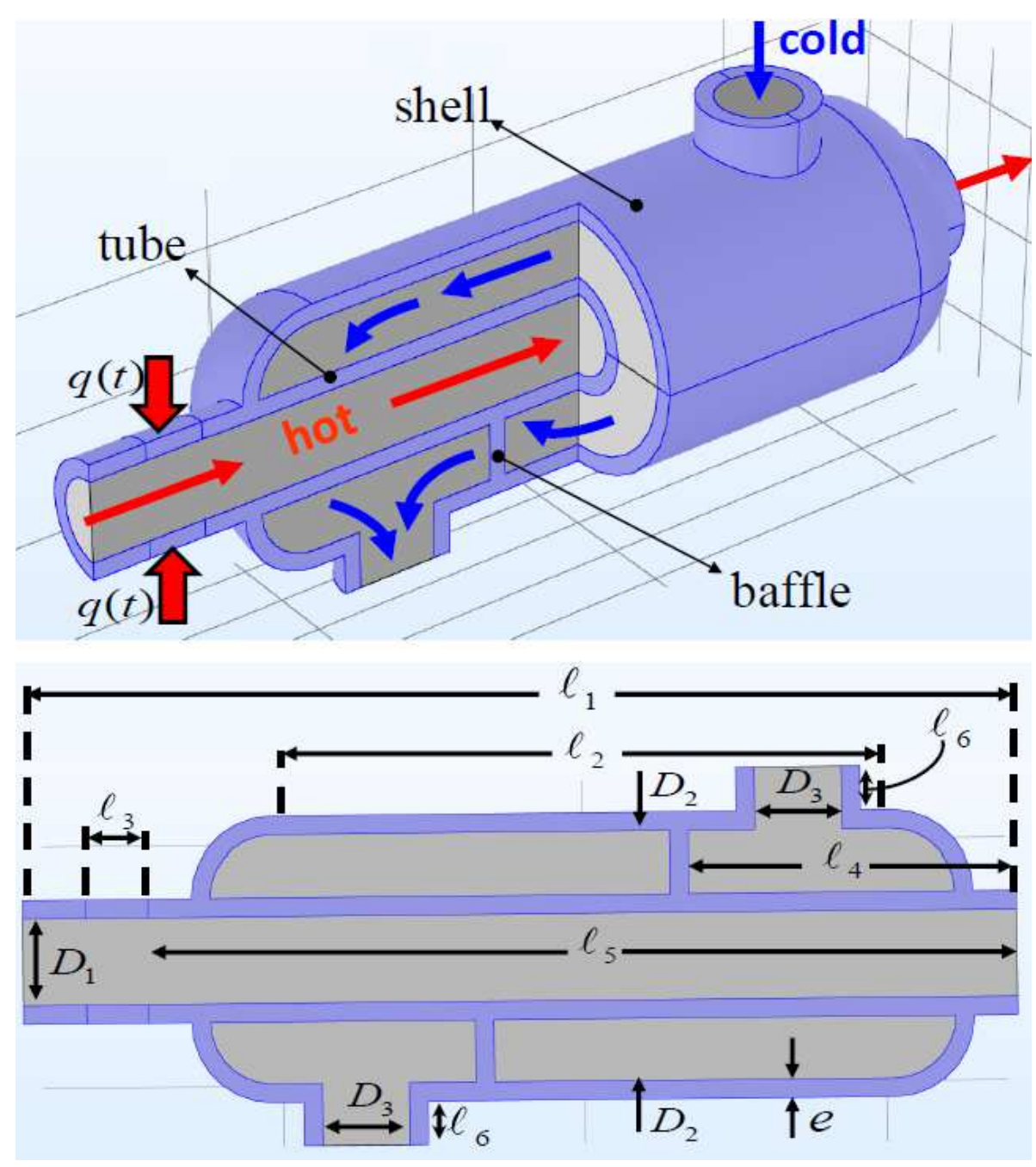

Fig. 1. Shell and tube heat exchanger and correponding dimensions.

$$
\begin{gathered}
\rho(\boldsymbol{v} . \nabla) \boldsymbol{v}=-\nabla P+\nabla \cdot\left[\left(\mu+\mu_{T}\right)\left(\nabla \boldsymbol{v}+(\nabla \boldsymbol{v})^{T}\right)\right]+\boldsymbol{F} \\
\rho(\boldsymbol{v} . \nabla) k=\nabla \cdot\left[\left(\mu+\frac{\mu_{T}}{\sigma_{k}}\right) \nabla k\right]+P_{k}-\rho \varepsilon \\
\rho(\boldsymbol{v} . \nabla) \varepsilon=\nabla \cdot\left[\left(\mu+\frac{\mu_{T}}{\sigma_{\varepsilon}}\right) \nabla \varepsilon\right]+C_{\varepsilon 1} \frac{\varepsilon}{k} P_{k}-C_{\varepsilon 2} \rho \frac{\varepsilon^{2}}{k}
\end{gathered}
$$

with $\mu_{T}=\rho C_{\mu} k^{2} / \varepsilon, P_{k}=\mu_{T}\left[\nabla \boldsymbol{v}:\left(\nabla \boldsymbol{v}+(\nabla \boldsymbol{v})^{T}\right)\right], C_{\varepsilon 1}=1.44, C_{\varepsilon 2}=1.92, C_{\mu}=0.09, \sigma_{k}=1$ and $\sigma_{\varepsilon}=1.3 . v$ is the velocity vector, the density, $\rho$ the density, $\mu$ the dynamic viscosity, $\mu_{T}$ the turbulent viscosity, $\boldsymbol{F}$ the external force per unit volume, $k$ the turbulent kinetic energy, $\varepsilon$ the rate of dissipation of the turbulent kinetic energy, while $\sigma_{k}, \sigma_{\varepsilon}, C_{\varepsilon 1}$ and $C_{\varepsilon 2}$ are empirical constants. 
A change of function is made in order to define the temperature variation $\theta$, that is the response to the surface heat perturbation $q(t)$ :

$$
\theta(x, y, z, t)=T(x, y, z, t)-T(x, y, z, t=0)
$$

The transient heat equation in the walls (tube, shell and baffles walls), in the fluid flow (hot and cold), the initial conditions and the boundary conditions (for heat and motion equations), are :

- Heat equation in the walls and in the fluid flows :

$$
\nabla^{2} \theta-\frac{1}{a_{i}} \boldsymbol{v} . \nabla \theta_{i}=\frac{1}{a_{i}} \frac{\partial \theta_{i}}{\partial t} \quad \text { with } \quad i=s \text { or } f
$$

Here, subscript $f$ designates the fluid domain while $s$ corresponds to the solid part of the system, where $\boldsymbol{v}=0$.

- Initial condition

$$
\theta_{i}(x, y, z, t=0)=0
$$

This condition means that the thermal perturbation $q(t)$ is applied at time $t=0$ on a system where a steady state had be reached for the initial temperature field $T(x, y, z, t=0)$.

- Boundary conditions

- at the fluid inlets, temperature variations and volume flow rates are imposed:

Inlet hot fluid temperature

Inlet cold fluid temperature

Inlet hot fluid volume flow rate

Inlet cold fluid flow rate

$$
\begin{aligned}
& \theta_{f}=\theta_{i n}^{h}(t) \\
& \theta_{f}=\theta_{i n}^{c}(t) \\
& \dot{Q}_{v}=\dot{Q}_{v}^{h} \\
& \dot{Q}_{v}=\dot{Q}_{v}^{c}
\end{aligned}
$$

- at the fluid outlets, heat flux and pressure are imposed.

Diffusion is neglected with respect to advection, because the Péclet numbers $P e$ (based on the outlet diameters $D_{1}$ and $D_{2}$ ) are high in our application :

$$
-\boldsymbol{n} \cdot \boldsymbol{q}_{\text {flux }}=0
$$

Pressure is also assumed to be uniform at the outlet of both hot and cold fluids, with a zero level here :

$$
P=0
$$

- the external fluid surfaces of the tubes and shell are supposed to be insulated :

$$
-\boldsymbol{n} \cdot \boldsymbol{q}_{\text {flux }}=0
$$

Equation (16) is valid everywhere, except over the cylindrical surface of length $\ell_{3}$ at the inlet of the hot fluid, see Figure 1, where the surface heat source $q(t)$ is applied ; 


$$
-\boldsymbol{n} . \boldsymbol{q}_{f l u x}=q(t)
$$

- at the solid/fluid interfaces, a continuity of temperatures and heat fluxes is assumed, with a zero local velocity.

In this work, the velocity field is assumed stationary and the thermophysical properties in the solid and in the fluid remain independent of temperature.

As a consequence, the considered system of equations (heat conduction and advection) (11) - (17)) that governs the transient temperature field $\theta$ is linear and time invariant, since the coefficients of these equations (including the velocity field $\boldsymbol{v}$ ) do not depend on time.

So, the convolution model (Equation $1 \mathrm{~b}$, in its scalar form, where $y$ is a temperature difference and $u$ is the perturbation heat flux $q$, remains valid. In this case, the temporal transfer function (impulse response) $H$ is called an impedance is denoted here $Z$, see [19]. The parameterized form $\boldsymbol{Z}=\boldsymbol{H}$ of the impedance can thus be identified by inverting vector equation (3b).

\section{Results and discussion}

The objective of this part is to validate numerically the principle of thermal fouling detector presented in section 2. The system represented in section 3 (tube and shell heat exchanger) has been modeled in 3D transient and simulated (after a mesh sensitivity study) by the commercial code COMSOL [22].

Two numerical experiments were made with two different temporal forms of the surface heat source $q(t)$ (thermal perturbation). In the first experiment, a constant surface heat source was applied from $t=0$ to $t=t_{\text {final }}$ (step function) where $t_{\text {final }}$ is the experiment duration. In the second experiment, a surface heat source that varies linearly with time, $t=0$ to $t=t_{\text {final }}$ (ramp function) was applied, such as $q(t)=K t$ where $K$ is the slope and $t$ is the time.

In these two experiments, we assumed that the flowing fluid in the tube (hot fluid) as well as that in the shell (cold fluid) were water and the solid walls (tube, shell and baffles) were supposed to be made out of steel (1C).

The corresponding thermophysical properties, that were assumed to be independent of temperature, are given in Table 2.

Table 2

Thermophysical properties of each medium.

\begin{tabular}{cccc}
\hline $\begin{array}{c}\lambda_{f} \\
\left(\mathrm{~W} \cdot \mathrm{m}^{-1} \cdot \mathrm{K}^{-1}\right)\end{array}$ & $\begin{array}{c}\rho c_{f} \\
\left(\mathrm{~kJ} \cdot \mathrm{m}^{-3} \cdot \mathrm{K}^{-1}\right)\end{array}$ & $\begin{array}{c}\lambda_{s} \\
\left(\mathrm{~W} \cdot \mathrm{m}^{-1} \cdot \mathrm{K}^{-1}\right)\end{array}$ & $\begin{array}{c}\rho c_{s} \\
\left(\mathrm{~kJ} \cdot \mathrm{m}^{-3} \cdot \mathrm{K}^{-1}\right)\end{array}$ \\
\hline 0.63 & 4186 & 44 & 3666 \\
\hline
\end{tabular}

The geometric parameters of these simulations, see Figure 1 are given in Table 3.

Table 3

Geometric parameters.

\begin{tabular}{lcccccccccc}
\hline Symbols & $\ell_{1}$ & $\ell_{2}$ & $\ell_{3}$ & $\ell_{4}$ & $\ell_{5}$ & $\ell_{6}$ & $D_{1}$ & $D_{2}$ & $D_{3}$ & $e$ \\
\hline Values $(\mathrm{mm})$ & 160 & 100 & 10 & 72.7 & 140 & 7 & 14 & 40 & 14 & 3 \\
\hline
\end{tabular}


The average velocity, $U_{m}$ calculated at the inlets, the volume flow rate, $\dot{Q}_{v}$ and the corresponding Reynolds number, $R e$ and Péclet number, $P e$ are given in Table $4:$ here the same volume flow rates were chosen for the hot and cold fluids, $\dot{Q}_{v}^{h}=\dot{Q}_{v}^{c}=\dot{Q}_{v}$. Since the inlet diameters were equal for the two fluids $\left(D_{1}=D_{3}\right.$, see Figure 1 and Table 3), the average velocities were also equal $\left(U_{m}^{h}=U_{m}^{c}=U_{m}\right)$ and since the two fluids were the same, therefore the correponding dimensionless numbers were equal $\left(R e^{h}=R e^{c}=R e\right.$ and $\left.P e^{h}=P e^{c}=P e\right)$.

\section{Table 4}

Average velocity and corresponding dimensionless numbers.

\begin{tabular}{lcccc}
\hline & $U_{m}\left({\left.\mathrm{~m} . \mathrm{s}^{-1}\right)}\right.$ & $\dot{Q}_{v}\left(\mathrm{~m}^{3} . \mathrm{s}^{-1}\right)$ & $R e=U_{m} D_{1} / v_{f}$ & $P e=\operatorname{Re} \operatorname{Pr}$ \\
\hline Hot and cold fluids & 0.01 & $1.5410^{-6}$ & 140 & 980 \\
\hline
\end{tabular}

Initially, in both numerical experiments, before thermal excitation (for $t \leq 0$ ), the temperature fields in the solid and in the fluid were stationary, so $(\theta(x, y, z, t=0)=0)$, see equations (10) and (12), and both inlet temperatures remained constant during the thermal excitation. This means that the only source of heat was the surface heat source $q(t)$. The temperature responses at each point in the system correponding to these two excitations forms $q(t)$ were calculated at each instant $t_{i}$ for $i=1$ to $N_{t}$ with $N_{t}=t_{\text {final }} / \Delta t$, for a time step $\Delta t=1 \mathrm{~s}$.

\subsection{Impulse response identification from $\theta_{\text {out }}^{h}$ and $\theta_{\text {out }}^{c}$ without fouling (calibration)}

The impulse response $H$ that connects the excitation (the thermal or power input) to its response in temperature, is noted $Z$. We consider here that the source is $q$ and its responses, the average temperatures at the outlet of the hot and the cold fluids are $\theta_{\text {out }}^{h}$ and $\theta_{\text {out }}^{c}$. The corresponding impulse responses are $Z_{h}$ and $Z_{c}$ respectively, see Figure 2.

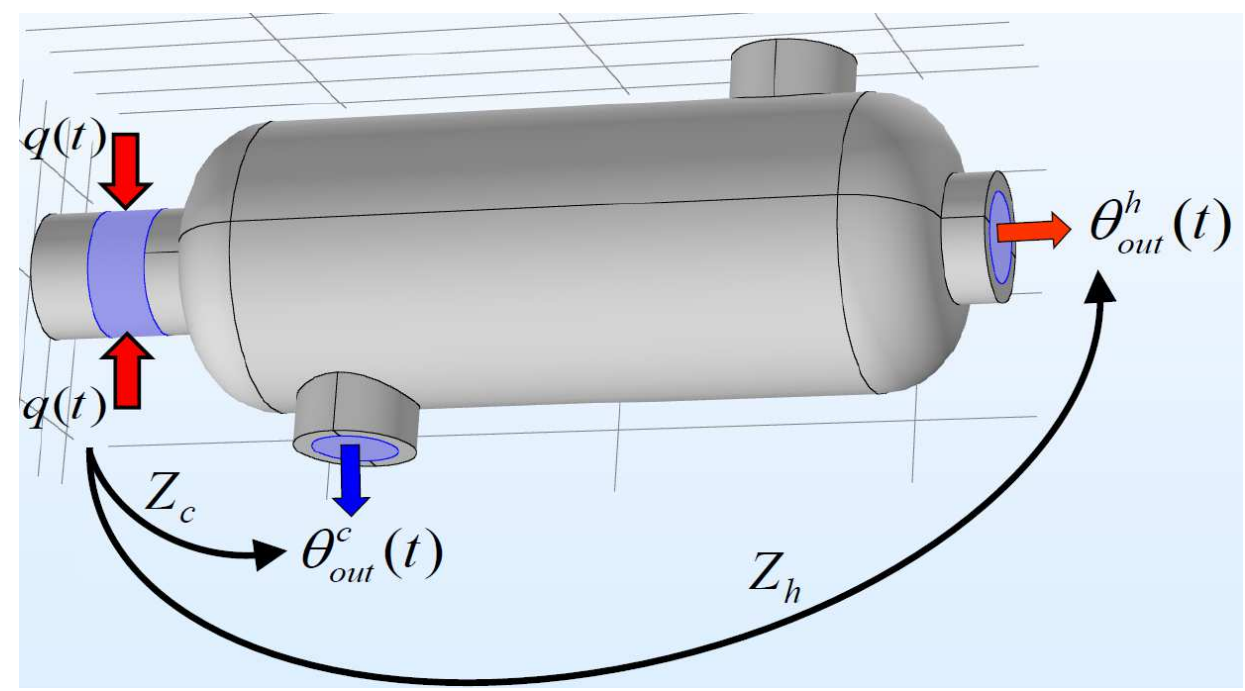

Fig. 2. Shell and tube heat exchanger and correponding impedances $Z_{h}$ and $Z_{c}$.

The evolution of the heat source, for each experiment (step and ramp) and of its responses are plotted in Figure 3 (step) and in Figure 4 (ramp). 


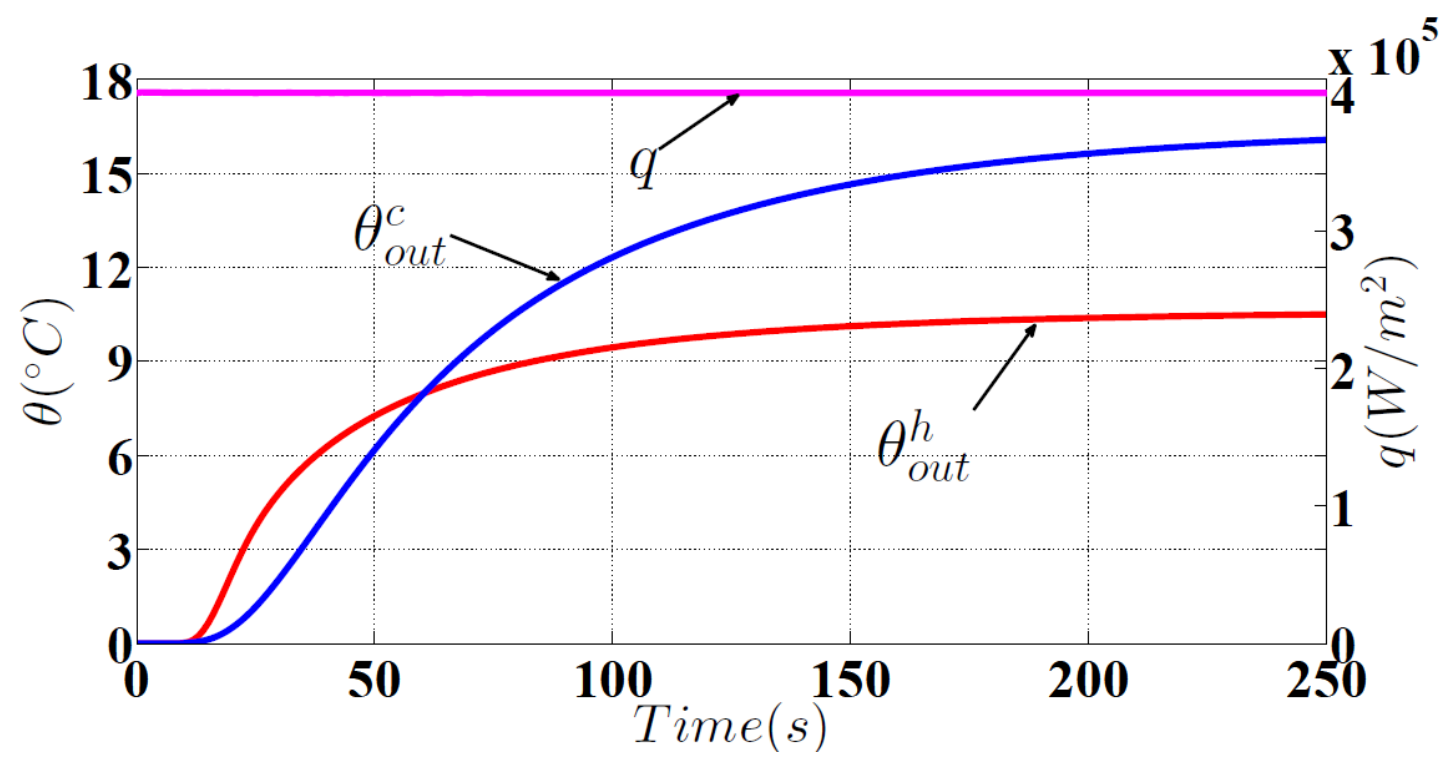

Fig. 3. Step excitation $q$ and corresponding average hot and cold outlet temperatures $\left(\theta_{\text {out }}^{h}\right.$ and $\left.\theta_{\text {out }}^{c}\right)$.

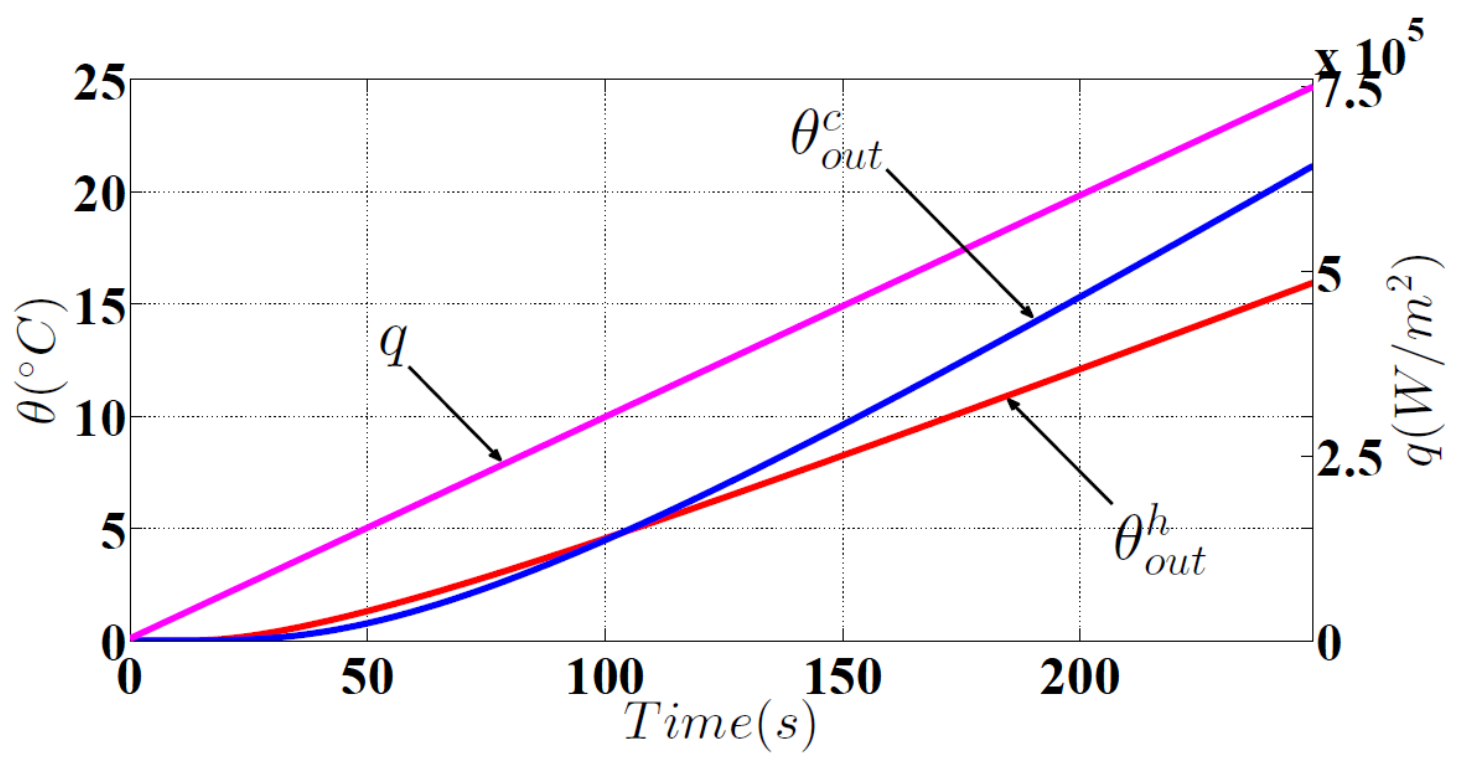

Fig. 4. Ramp excitation $q$ and corresponding average hot and cold outlet temperatures $\left(\theta_{\text {out }}^{h}\right.$ and $\left.\theta_{\text {out }}^{c}\right)$.

Starting from these synthetic profiles, the impulse responses, $Z_{h}$ and $Z_{c}$, have been identified using the convolutive model (Equation $3 b$ ) or by the semi-analytic expressions given in Table 1. These identified impedances are plotted in Figure 5, for step and ramp excitation.

The initial zero values for $Z_{h}$ and $Z_{c}$, (for $t<9 \mathrm{~s}$ ) mean that temperature signals $\theta_{\text {out }}^{h}$ and $\theta_{\text {out }}^{c}$ need a finite amount of time to react (the thermal disturbance has not yet arrived). For large times, the impulse response returns asymptotically to zero at $t \square 250 \mathrm{~s}$ for $Z_{c}$ and earlier for $Z_{h}$. This corresponds to the maximum duration of the response and can be considered as a local relaxation time of the system or a time necessary to reach a final steady state level in the outlet cross sections for a step excitation. In between these two extreme times, a unique maximum exists that gives information about the level of each response. It will be shown in a remark in subsection 4.3 further on that the larger the area below each impulse response is, the larger the corresponding "resistance" between the source and the outlet temperature of each fluid becomes.

Figure 5 shows that the modeled shell and tube heat exchanger behaves as a LTI system, since the identified impulse response, here an impedance, is independent of the excitation form (it is an intrinsic quantity and 
can be considered as a signature of the system). It also shows that the two methods of identification give the same results.

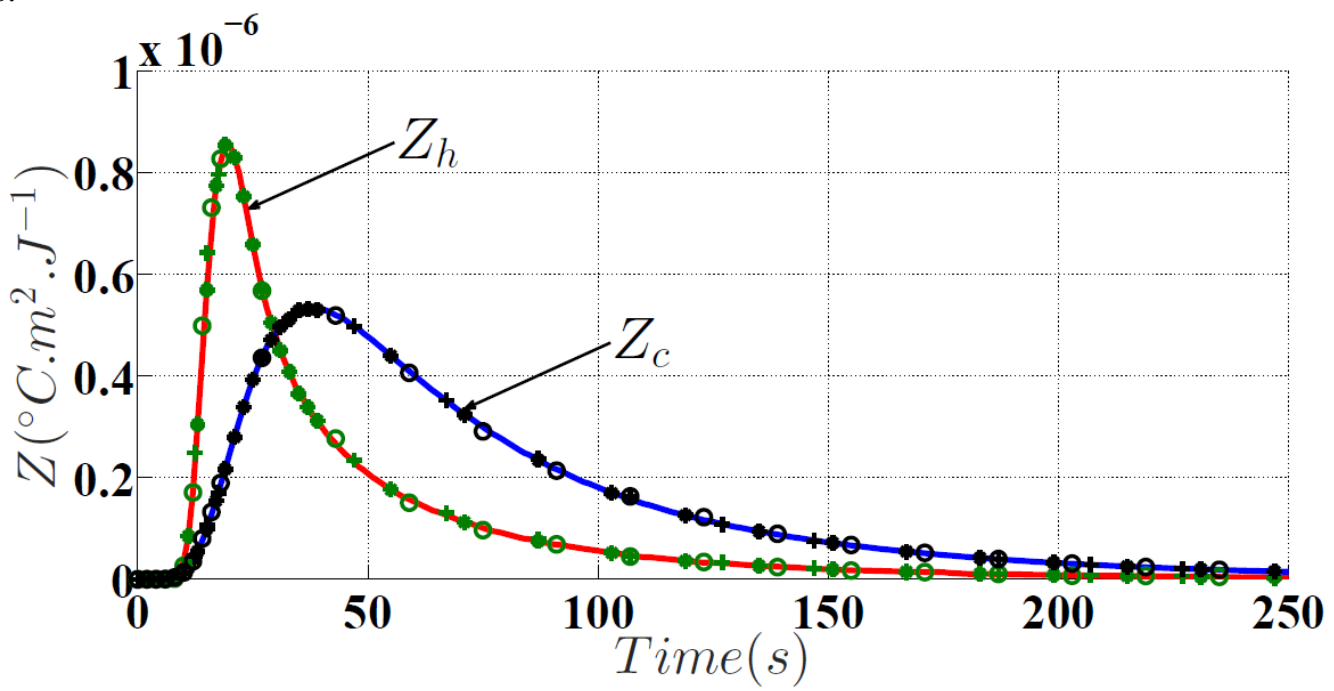

Fig. 5. Identified $Z_{h}$ and $Z_{c}$ from step and ramp excitations : continuous line (identified from step and equation (3b)), o (identified from ramp and equation ( $3 b)$ ), + (identified from step and by Table 1 ) and * (identified from ramp and by Table 1 ).

\subsection{Impulse response identification from $\theta_{\text {out }}^{h}$ and $\theta_{\text {out }}^{c}$ with fouling}

In this section, we will show the sensitivity of the impulse response to fouling. A fouling layer (limestone deposit) of uniform thickness $e_{c}$ is added over the hot face of the wall separating the two fluids in the system considered above, see Figure 6.

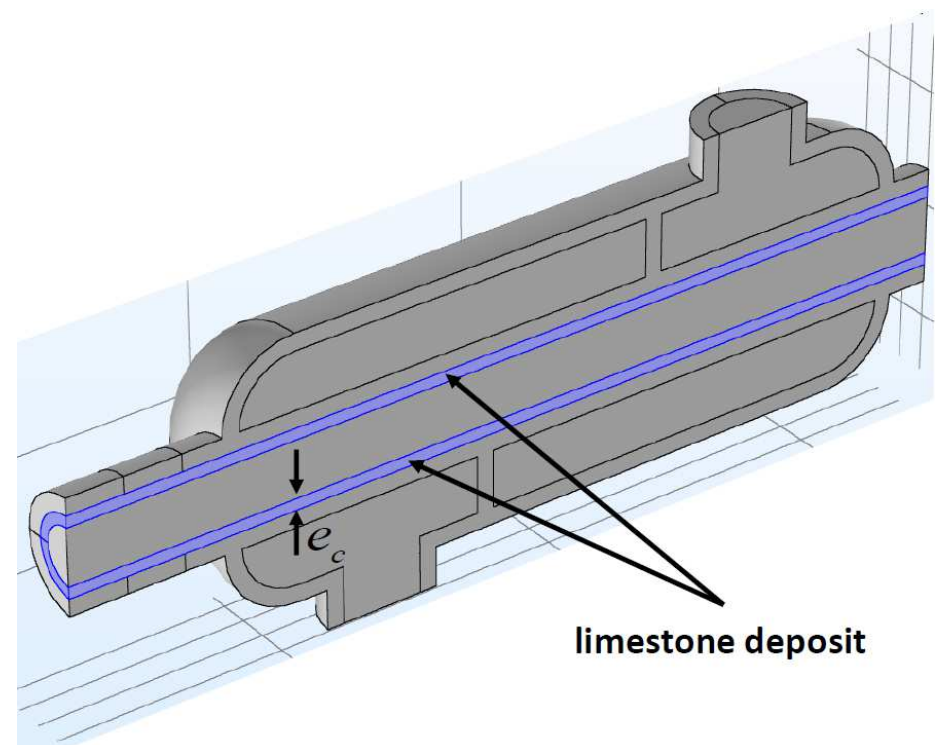

Fig. 6. Shell and tube heat exchanger with fouling.

The considered fouling layer is characterized by a thermal conductivity $\lambda_{c}=1.2 \mathrm{~W} \cdot \mathrm{m}^{-1}$. a density $\rho_{c}=2500$ $\mathrm{kg} \cdot \mathrm{m}^{-3}$ and a heat capacity at constant pressure, $c_{c}=760 \mathrm{~J} \cdot \mathrm{kg}^{-1} \cdot \mathrm{K}^{-1}$. After adding this fouling layer of different thicknesses $\left(e_{c}=1 \mathrm{~mm}\right.$, and then $e_{c}=2 \mathrm{~mm}$ ) to the system considered in section 4.1 and keeping the same flow rate ( $\dot{Q}_{v}=1.5410^{-6} \mathrm{~m}^{3} . \mathrm{s}^{-1}$ ), the corresponding impulse responses (with fouling) were reidentified and are plotted in Figure 7 for $Z_{h}$ and in Figure 8 for $Z_{c}$. In the same figures, the corresponding impulse responses without fouling are also plotted. 


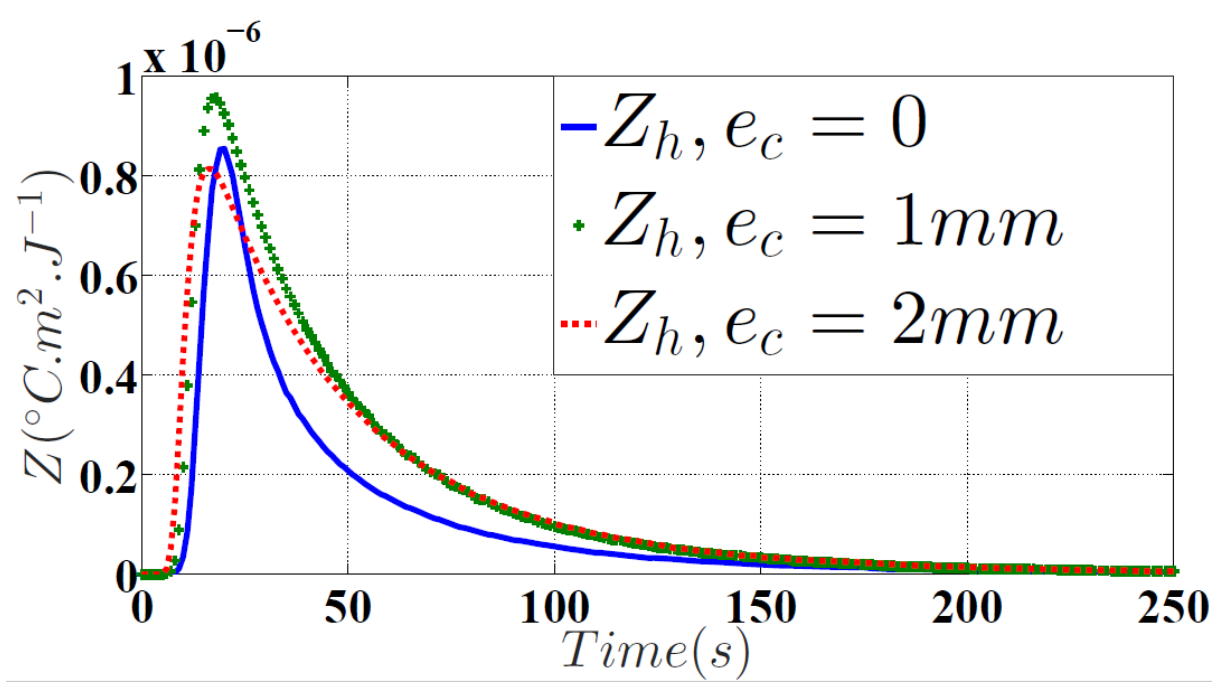

Fig. 7. Identified $Z_{h}$ without $\left(e_{c}=0\right)$ and with fouling layer of uniform thickness $e_{c}=1 \mathrm{~mm}$ and $e_{c}=2 \mathrm{~mm}$.

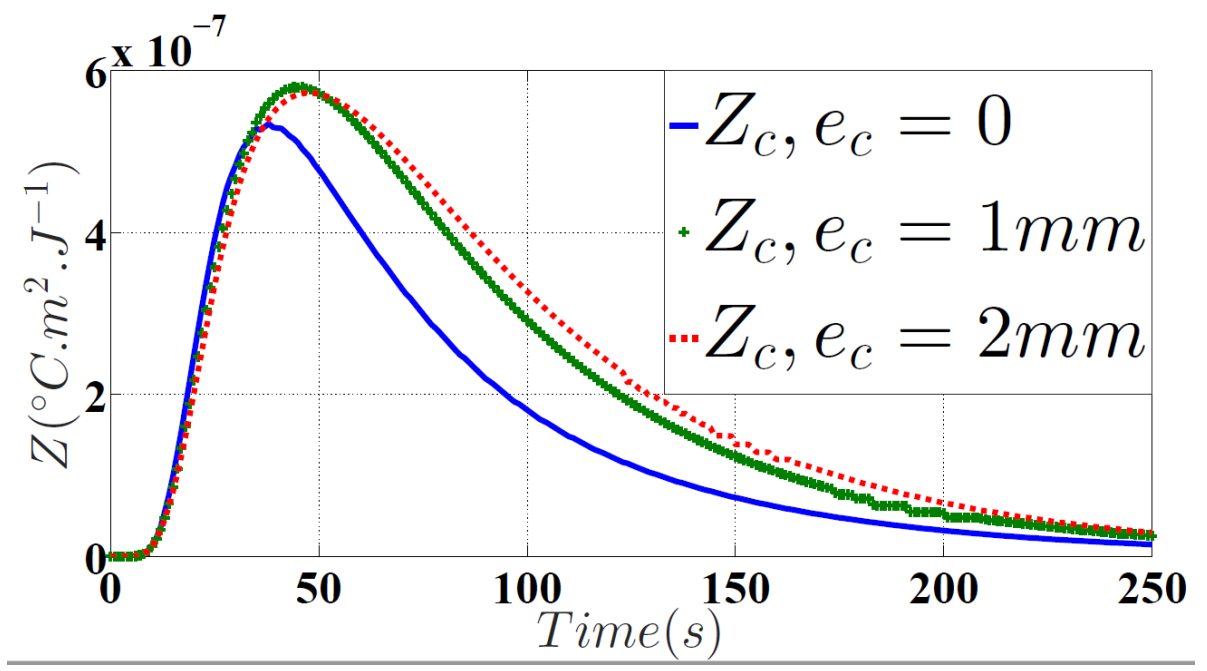

Fig. 8. Identified $Z_{c}$ without $\left(e_{c}=0\right)$ and with fouling layer of uniform thickness $e_{c}=1 \mathrm{~mm}$ and $e_{c}=2 \mathrm{~mm}$.

It can be seen in Figures 7 and 8 that presence of a fouling layer tends to modify the impulse responses profiles : the increase in the thickness (resistance) of this layer leads to a change in the area below each curve : this one gets smaller for $Z_{h}$ and larger for $Z_{c}$. It also leads to an increase in the time required to reach their asymptotic zero levels.

\subsection{Impulse response identification from external wall temperatures $\theta_{w}^{h}$ and $\theta_{w}^{c}$ with fouling}

In some applications, an instrumentation for internal (fluid) temperature measurements is not convenient and the measurements of the local or average temperature of the outer wall surfaces of both fluids is much simpler. The impulse response principle is extrapolated here in order to design a Non-Destructive Testing (NDT) method : instead of identifying the impulse response from the fluid temperatures (see sections 4.1 and 4.2 where the impulse response has been identified from $\theta_{\text {out }}^{h}$ and $\theta_{\text {out }}^{c}$ ), we will identify it from 
the external wall average temperatures $\theta_{w}^{h}$ and $\theta_{w}^{c}$ at the outlets, see Figure 9. The corresponding impedances are noted $Z_{h}^{w}$ and $Z_{c}^{w}$.

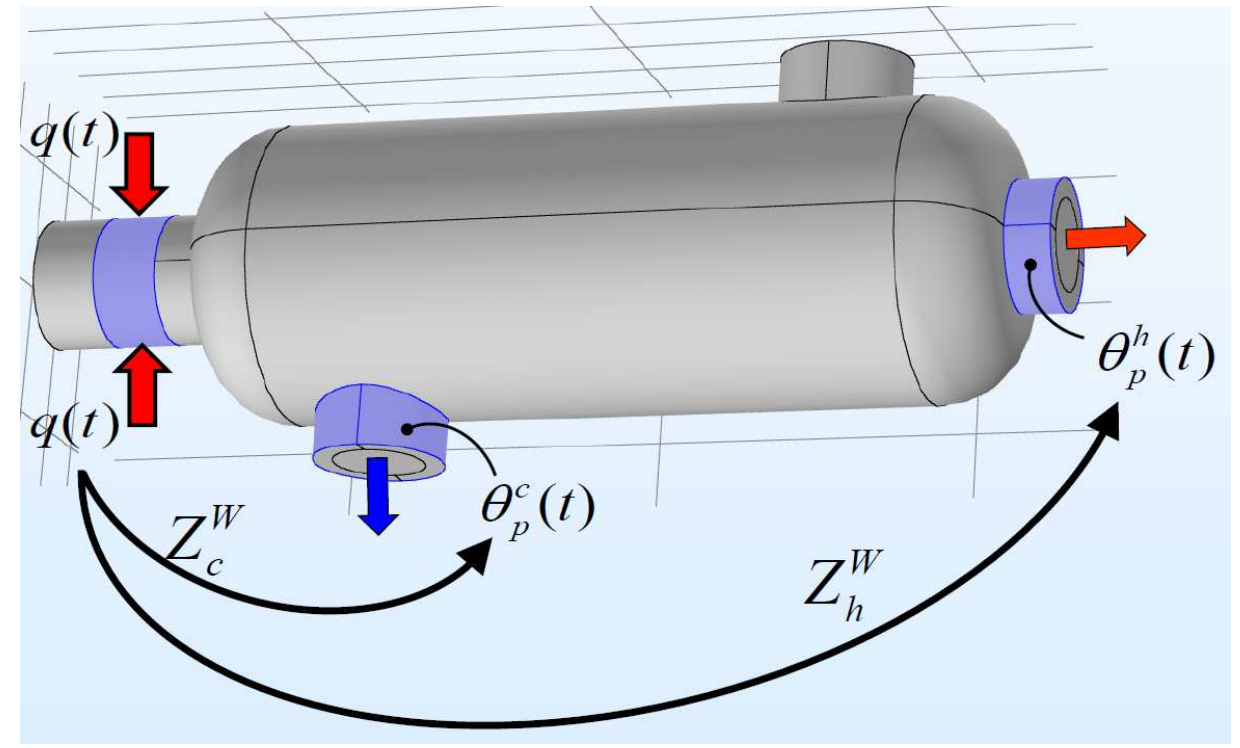

Fig. 9. Shell and tube heat exchanger and correponding impedances $Z_{h}^{w}$ and $Z_{c}^{w}$.

The impulse responses identified starting form the external temperatures profiles $\theta_{w}^{h}$ and $\theta_{w}^{c}$, without and with fouling are plotted in Figure 10 for $Z_{h}^{w}$ and in Figure 11 for $Z_{c}^{w}$. These figures show that the sensitivity of the impulse responses to fouling are high (higher than the corresponding impedance for outlet fluid observation in the hot fluid case, see Figure 7) and that they can be used non-intrusively to detect fouling in the present case.

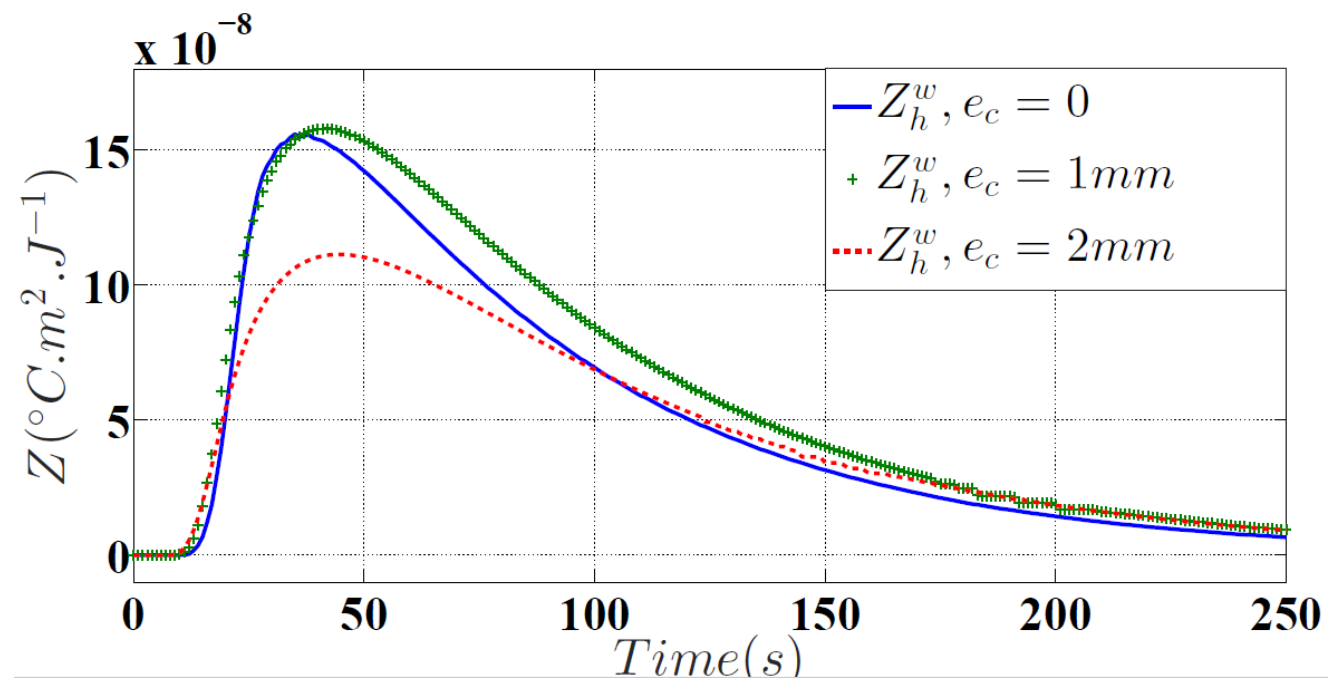

Fig. 10. Identified impedances $Z_{h}^{w}$ without and with a fouling layer of uniform thickness $e_{c}=1 \mathrm{~mm}$ and $e_{c}=2 \mathrm{~mm}$. 


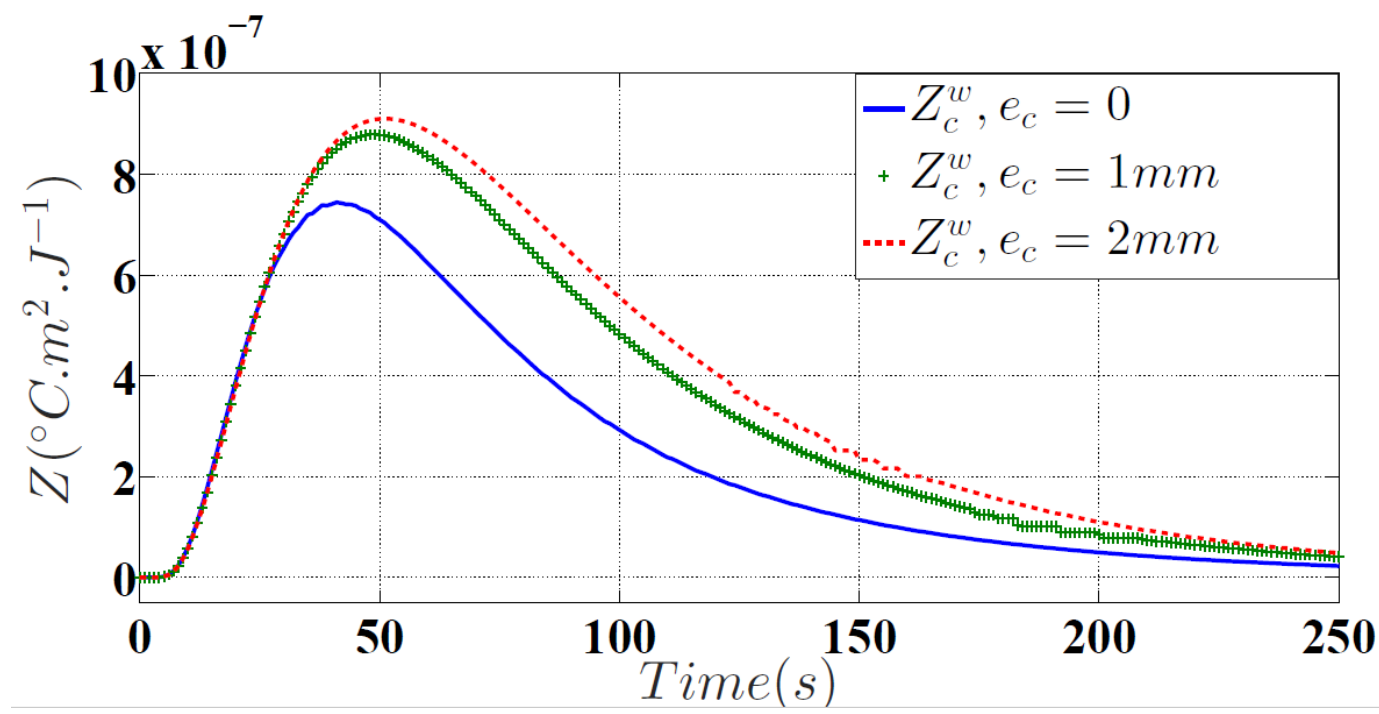

Fig. 11. Identified impedances $Z_{c}^{w}$ without and with a fouling layer of uniform thickness $e_{c}=1 \mathrm{~mm}$ and

$$
e_{c}=2 \mathrm{~mm} \text {. }
$$

\subsection{Interest of integrating the identified impedances with respect to time}

As it was shown in $[19,20]$, an impulse response or impedance $Z(t)$ can be written in steady state and this writing corresponds in fact to a thermal resistance, noted here $Z^{s s}$, superscript ss designating a steady state value here. The latter can be calculated from the impulse response itself, see equation (18a) or from the asymptotic value of the source $q^{s s}$ and of the corresponding response $\theta^{s s}$, see equation (18b) :

$$
\begin{aligned}
& Z^{s s}=\int_{0}^{\infty} Z(t) \mathrm{d} t \\
& Z^{s s}=\theta^{s s} / q^{s s}
\end{aligned}
$$

By integrating each impulse response profile (see Figure 7, Figure 8, Figure 10 and Figure 11) for step or ramp excitation or by calculating its steady state value by the ratio of the asymptotic value of excitation $q^{s s}$ to the response $\theta^{s s}$ (these last values are available for the step excitation only) one obtains the corresponding steady state impedance (it corresponds to a generalized thermal resistance), $Z^{s s}$. The obtained values are given in Table 5 .

\section{Table 5}

Identified steady state impedances (in $\mathrm{K} . \mathrm{m}^{2} . \mathrm{W}^{-1}$ ) from the temporal distribution of the tranisent impedances (impulse response) or from the asymptotic values of the source $q^{s s}$ and the responses $\theta^{s s}$.

\begin{tabular}{lcccc}
\hline & \multicolumn{2}{c}{ Internal measurements } & \multicolumn{2}{c}{ External measurements } \\
\hline & $\begin{array}{c}Z_{h}^{s s} \times 10^{5} \\
\left(\mathrm{~K} . \mathrm{m}^{2} . \mathrm{W}^{-1}\right)\end{array}$ & $\begin{array}{c}Z_{c}^{s s} \times 10^{5} \\
\left(\mathrm{~K} . \mathrm{m}^{2} . \mathrm{W}^{-1}\right)\end{array}$ & $\begin{array}{c}Z_{h}^{w, s s} \times 10^{5} \\
\left(\mathrm{~K} . \mathrm{m}^{2} . \mathrm{W}^{-1}\right)\end{array}$ & $\begin{array}{c}Z_{c}^{w, s s} \times 10^{5} \\
\left(\mathrm{~K}^{2} \mathrm{~m}^{2} . \mathrm{W}^{-1}\right)\end{array}$ \\
\hline no fouling $\left(e_{c}=0\right)$ & 2.62 & 4.02 & 1.34 & 6.15 \\
\hline with fouling $\left(e_{c}=1 \mathrm{~mm}\right)$ & 4.02 & 5.31 & 1.55 & 8.50 \\
\hline with fouling $\left(e_{c}=2 \mathrm{~mm}\right)$ & 3.87 & 5.65 & 1.22 & 9.37 \\
\hline
\end{tabular}


This table shows that the steady state impedance $Z^{s s}$ increases with fouling, except for $Z_{h}^{s s}$ and $Z_{h}^{w, s s}$ for $e_{c}=2 \mathrm{~mm}$, because in this case, presence of the fouling insulating layer favours direct transfer from the source to the cold fluid at the expense of the hot fluid.

Variation of steady state impedances, that are generalized thermal resistances, constitutes a convenient tool for fouling detection, even it they have to be interpreted with some hindsight. Their transient versions bring many more informations since they are functions and not scalars [25].

\section{Conclusions}

We have proposed here a method for fouling detection in a heat exchanger or any thermal device whose model equations are linear and time invariant. The presented method is based on the variation of the impulse response that characterizes the system (thermal signature) with fouling. The idea here is to identify the model that describes the transfer from measurements on the system itself, that is via an experimental calibration (the identification phase). This identification, on a clean and then on an operating system, can replace fouling detection by a classical method based on estimation on the thermal parameters of a detailed model, that is the equations of the system, with boundary conditions and initial conditions with simplifying assumptions. This allows to make assumptions that are unavoidable in a classical modeling attempt. Indeed, the identified impulse response takes into account all the effects that are difficult to model implicitely: wall roughness, turbulence, contact resistance, defect in the materials that can have thermophysical properties different from their a priori known nominal values, etc.

In order to validate the concept of this method, it was applied here to output data of a numerical model of a tube and shell heat exchanger, where a thermal disturbance was made by a surface heat source located upstream the hot fluid inlet. The temperature responses were calculated at the outlets of the hot and cold fluids or on the external wall surfaces of the corresponding cross sections using a Computational Fluid Dynamics code, COMSOL. Three results were obtained :

i) The impulse response, that depends on the definition of the way the thermal excitation is applied and on the location where the temperature response is measured, is able to reproduce the temperature outputs of the detailed model through its use in a specific reduced model, that is the convolution product with the input ;

ii) The estimated impulse response does not depend on the time shape of the excitation ;

iii) The impulse response is sensible to the presence of a fouling deposit.

So, this concept verification study shows that the impulse response is an intrinsic quantity and can be used to detect fouling in a heat exchanger. Let us note that the present technique has already been tested experimentally for a flat plate heat exchanger, see [26].

\section{Acknowledgment}

The authors want to thank the FEDER European Fund as well as Région Grand Est who funded this work run within the EPHAISTOS project.

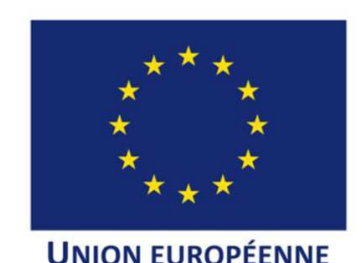

UNION EUROPÉENNE Fonds Européen de Développement Régional

\section{References}

[1] T. R. Bott, Fouling of heat exchangers, Elsevier Science, 1995. 
[2] E. Diaz-Bejarano, E. Behranvand, E., F. Coletti, M.R. Mozdianfard, S. Macchietto, Organic and inorganic fouling in heat exchangers: Industrial case study analysis of fouling rate, Industrial and Engineering Chemistry Research 58 (2019), 228-246. https://pubs.acs.org/doi/10.1021/acs.iecr.8b04343.

[3] Y. Guo, G. Li, H. Chen, J. Wang, M. Guo, M., S. Sun, W. Hu, Optimized neural network-based fault diagnosis strategy for VRF system in heating mode using data mining, Applied Thermal Engineering 125 (2017) 1402-1413. https://doi.org/10.1016/j.applthermaleng.2017.07.065.

[4] W. Al Hadad, Heat transfer in mini-channels : unsteady behaviour and convolutive approach, (in French : Thermique des mini-canaux : comportement instationnaire et approche convolutive). $\mathrm{PhD}$ thesis, Université de Lorraine, Sept.22, 2016.

[5] O. Gudmundsson, S. Lalot, and J. Thorsen, Comparison of fouling detection methods using experimental data, Proc. on Heat Exchanger Fouling and Cleaning X-2013, 09-14, 2013.

[6] O. Gudmundsson, O.P. Palsson, H. Palsson, S. Lalot, Online fouling detection of domestic hot water heat exchangers, Heat Transfer Engineering 37, (2016), issue 15, 1231-1241.

https://doi.org/10.1080/01457632.2015.1119584.

[7] K. A. Palmer, G. M. Bollas, Analysis of transient data in test designs for active fault detection and identification, Computers and Chemical Engineering 000 (2018) 1-12., Article in Press. https://doi.org/10.1016/j.compchemeng.2018.06.020.

[8] D.C. Pham, G. Mercère, R. Ouvrard, T. Poinot, H. Pálsson, Fouling detection in a parallel flow heat exchanger via a Roesser model identification procedure, IFAC PapersOnLine 50-1 (2017) 12866-12871.

[9] S. Lalot, B. Desmet, Analysis of the unsteady behavior of an electrical heater using the lock-in technique: Comparison of theory and experiments, Applied Thermal Engineering 79 (2015) 37-43. https://doi.org/10.1016/j.compchemeng.2018.06.020.

[10] S. Lalot, B. Desmet, The lock-in technique applied to heat exchangers: A semi-analytical approach and its application to fouling detection, Applied Thermal Engineering 114 (2017) 154-162. http://dx.doi.org/10.1016/j.applthermaleng.2016.11.174.

[11] G. R. Jonsson, S. Lalot, O. P. Palsson, and B. Desmet, Use of extended Kalman filtering in detecting fouling in heat exchangers, International Journal of Heat and Mass Transfer, vol. 50 (2007) 12643-2655, 2007. https://doi.org/10.1016/j.ijheatmasstransfer.2006.11.025.

[12] S. Delrot, T. M. Guerra, M. Dambrine, and F. Delmotte, Fouling detection in a heat exchanger by observer of Takagi-Sugeno type for systems with unknown polynomial inputs, Engineering Applications of Artificial Intelligence, 25 (2012) 1558-1566. https://doi.org/10.1016/j.engappai.2012.08.004.

[13] K. A. Palmer, W. T. Hale, K. D. Such, B. R. Shea, and G. M. Bollas, Optimal design of tests for heat exchanger fouling identification, Applied Thermal Engineering 95 (2016) 382-393.

http://dx.doi.org/10.1016/j.applthermaleng.2015.11.043.

[14] H. Herwig, Flow and heat transfer in micro systems : Is everything different or just smaller ?," ZAMM 82 (2002) no. 9, 579-586.

[15] H. Herwig and O. Hausner, Critical view on "new results in microfluid mechanics : an example, International Journal of Heat and Mass Transfer 46 (2003) no. 5, 935-937.

[16] Z.-Y. Guo and Z.-X. Li, Size effect on microscale single-phase flow and heat transfer, International Journal of Heat and Mass Transfer 46 (2003) no. 1, 149-159.

[17] M. Stenberg, G. Stemme, G. Kittilsland, and K. Pedersen, A silicon sensor for measurement of liquid flow and thickness of fouling biofilms, Sensors and actuators 13 (1988) no. 3, 203-221. 
[18] P. M. Withers, Ultrasonic, acoustic and optical techniques for the noninvasive detection of fouling in food processing equipment, Trends in food science \& technology 7 (1996) no. 9, 293-298.

[19] W. Al Hadad, D. Maillet, and Y. Jannot, Modeling unsteady diffusive and advective heat transfer for linear dynamical systems : A transfer function approach, International Journal of Heat and Mass Transfer 115 (2017) 304-313. International Journal of Heat and Mass Transfer 115 (2017) 304-313. http://dx.doi.org/10.1016/j.ijheatmasstransfer.2017.07.009.

[20] W. Al Hadad, D. Maillet, and Y. Jannot, Experimental transfer functions identification : Thermal impedance and transmittance in a channel heated by an upstream unsteady volumetric heat source, International Journal of Heat and Mass Transfer 116 (2018) 931-939. International Journal of Heat and Mass Transfer 116 (2018) 931-939. https://doi.org/10.1016/j.ijheatmasstransfer.2017.09.079.

[21] W. Al Hadad, D. Maillet, Y. Jannot, and V. Schick, Inverse conduction and advection in a flat channel with transient external thermal excitation and observation, International Journal of Heat and Mass Transfer, 127 (2018) 362-372. https://doi.org/10.1016/j.ijheatmasstransfer.2018.05.142.

[22] COMSOL Multiphysics version 5.3. https://www.comsol.fr.

[23] F. Chata, E. Belut, D. Maillet, F.-X. Keller, A. Taniere, Estimation of an aerosol source in forced ventilation through prior identification of a convolutive model, International Journal of Heat and Mass Transfer 108 (2017) 1623-1644. http://dx.doi.org/10.1016/j.ijheatmasstransfer.2017.01.015.

[24] W. Jones and B. Launder, "The prediction of laminarization with a two equation model of turbulence," International Journal of Heat and Mass Transfer, 15 (1972) no. 2, 301-314.

[25] W. Al Hadad, Y. Jannot, and D. Maillet, Characterization of a heat exchanger by virtual temperature sensors based on identified transfer functions, Journal of Physics : Conference Series 745 (2016) 032089.

[26] W. Al Hadad, V. Schick, and D. Maillet, Fouling detection in a heat exchanger using variation of its thermal transfer functions : an experimental approach, Applied Thermal Engineering Journal, to be submitted, March 2019. 